JOSECLEYTON GERALDO DA SILVA

PONDERAÇÃO, OTIMIZAÇÃO E DEMOCRACIA: PARÂMETROS DOGMÁTICOS PARA O CONTROLE JUDICIAL DE CONSTITUCIONALIDADE DA LEGISLAÇÃO RESTRITIVA DE DIREITOS FUNDAMENTAIS

\author{
DISSERTAÇÃO DE MESTRADO \\ Orientador: Professor Titular Dr. Virgílio Afonso da Silva
}

UNIVERSIDADE DE SÃO PAULO

FACULDADE DE DIREITO

SÃO PAULO 
JOSECLEYTON GERALDO DA SILVA

\title{
PONDERAÇÃO, OTIMIZAÇÃO E DEMOCRACIA: PARÂMETROS DOGMÁTICOS PARA O CONTROLE JUDICIAL DE CONSTITUCIONALIDADE DA LEGISLAÇÃO RESTRITIVA DE DIREITOS FUNDAMENTAIS
}

\begin{abstract}
Dissertação apresentada a Banca Examinadora do Programa de Pós-Graduação em Direito, da Faculdade de Direito da Universidade de Paulo, como requisito parcial para obtenção do título de Mestre em Direito, na área de concentração Direito do Estado, sob orientação do Prof. Titular Dr. Virgílio Afonso da Silva.
\end{abstract}

UNIVERSIDADE DE SÃO PAULO

FACULDADE DE DIREITO

SÃO PAULO 
ANEXO I - FOLHA DE APROVAÇÃO

JOSECLEYTON GERALDO DA SILVA

PONDERAÇÃO, OTIMIZAÇÃO E DEMOCRACIA: PARÂMETROS DOGMÁTICOS PARA O CONTROLE JUDICIAL DE CONSTITUCIONALIDADE DA LEGISLAÇÃO RESTRITIVA DE DIREITOS FUNDAMENTAIS

Dissertação apresentada a Banca Examinadora do Programa de Pós-Graduação em Direito, da Faculdade de Direito da Universidade de Paulo, como requisito parcial para obtenção do título de Mestre em Direito, na área de concentração Direito do Estado, sob orientação do Prof. Titular Dr. Virgílio Afonso da Silva.

BANCA EXAMINADORA: 


\section{AGRADECIMENTOS}

A despeito da solidão que no mais das vezes caracteriza a pesquisa acadêmica, é comum a afirmação de que a produção científica é sempre uma obra coletiva. Essa afirmação é justa, porque, mesmo nas hipóteses de trabalhos formalmente com um único autor, o seu resultado nunca depende de apenas uma pessoa. Tantas outras contribuem direta e indiretamente para ele. Por isso, é imprescindível agradecer aqui àqueles que de uma forma ou de outra foram importantes para que esta dissertação se tornasse uma realidade.

Ao meu orientador, Professor Virgílio Afonso da Silva, agradeço não apenas pela confiança, pela orientação neste trabalho e pela disposição para discutir cada um de seus pontos, criticar e fazer sugestões, algo de resto essencial à sua elaboração, mas, para além disso, pelo incentivo à crítica e ao debate sério na academia e pelo exemplo de postura e dedicação à docência.

Agradeço também aos Professores Conrado Hübner Mendes e Marcos Paulo Veríssimo - membros da banca examinadora de qualificação - pelos comentários, críticas e sugestões - seja no próprio exame de qualificação, seja nas oportunidades em que expus e discuti algumas ideias deste trabalho nos seminários de pesquisa do grupo Constituição, Política e Instituições - que me fizeram tanto corrigir alguns rumos quanto aprimorar argumentos. E por isso devo agradecer também a todos os colegas daquele grupo, que, em várias ocasiões, trouxeram importantes contribuições para esta dissertação. Também tive a oportunidade de discutir parte deste trabalho com os colegas do grupo de discussões em direito público e teoria do direito PósDebate, e mais uma vez recebi sugestões e críticas de grande valia, razão pela qual sou grato a todos eles.

Agradeço a Antônio Sérgio de Moraes Pitombo e a todos aqueles que fazem o Moraes Pitombo Advogados por todo o apoio que recebi durante esta empreitada. Gostaria de agradecer também aos funcionários das bibliotecas da Faculdade de Direito da Universidade de São Paulo, que muito me ajudaram durante o período de realização desta dissertação, inclusive mediando a obtenção de obras junto a bibliotecas de outros países. Sem tal auxílio, o acesso a esse material - ou pelo menos a grande parte dele - teria sido impossível. 
Não poderia deixar de agradecer aos amigos da Pós Graduação: Henrique Leite, Guilherme Kamitsuji, Virgínia Adami e Rafael Bellem de Lima, com quem também discuti sobre vários pontos desta dissertação ao longo dos últimos anos. Agradeço também aos amigos, de Triunfo e de São Paulo, Rodolfo Costa, Tarcízio Filho, Renato Santos, Paulo Santos, William Araújo e Uilton Araújo, Larissa Lino, Jackeline Kimura e Bruno Zago.

Por fim, agradeço à minha família, em especial aos meus irmãos e à minha mãe, Helena, pelo apoio incondicional em todos os momentos da minha vida. Sem esse apoio, não há dúvida, a possibilidade de escrever uma dissertação no âmbito do programa de PósGraduação da Faculdade de Direito da Universidade de São Paulo seria algo inimaginável. Por esta razão, este trabalho pertence menos a mim e mais a eles. 


\section{RESUMO}

Umas das objeções mais frequentes ao sopesamento é a suposta ilegitimidade de sua utilização pelo Judiciário. No contexto da sua leitura como otimização, dois aspectos relacionados a essa crítica assumem relevo: sustenta-se tanto que a ponderação otimizante não é capaz de limitar a atuação do legislador e, portanto, não possibilita uma proteção adequada dos direitos fundamentais, por permitir que ele desrespeite diuturnamente a moldura constitucional, quanto que, como ela constitui, no fim das contas, a busca pela única resposta correta, seu uso retira do legislador toda e qualquer liberdade para conformar a Constituição, desfazendo, pois, aquela moldura mediante uma ampliação ao extremo da competência de controle do tribunal constitucional. Para responder a estas críticas, Robert Alexy desenvolve a noção de discricionariedades legislativas no âmbito da sua teoria dos princípios. O objetivo deste trabalho é, precisamente, analisar como as espécies de discricionariedade legislativas podem funcionar como limites ao uso do sopesamento pelo Judiciário quando do controle de constitucionalidade de leis que restringem direitos fundamentais. A partir de algumas premissas que delimitam o marco teórico do trabalho, quais sejam, a teoria dos princípios de Robert Alexy, as teorias do suporte fático amplo e externa dos direitos fundamentais, a noção de Constituição como ordem moldura e o conceito de restrição a direitos fundamentais, procura-se esclarecer as duas formas construir esses limites, a discricionariedade estrutural para sopesar e as discricionariedades epistêmicas. Tomando como ponto de partida as discussões da teoria do direito, sustenta-se que, quando se fala em discricionariedade estrutural para sopesar, a discricionariedade deve ser entendida como um tipo especial de escolha, significativamente restringida pela razão e pelo papel institucional, e que tal discricionariedade, que surge em decorrência do reconhecimento de um empate no sopesamento, incide sobre uma situação que, do ponto de vista estrutural, constitui um verdadeiro dilema moral genuíno e indica um âmbito constitucionalmente não valorado. Considerados tais aspectos, por força do princípio formal da competência do legislador democraticamente legitimado, é necessário que o tribunal adote uma postura de deferência com relação à decisão legislativa. No que se refere às discricionariedades epistêmicas do legislador, tanto de tipo empírico quanto de tipo normativo, surgidas respectivamente em decorrência da insegurança das premissas empíricas e normativas, sustenta-se que a discricionariedade neste contexto deve ser vista de modo conceitualmente diverso da forma como o fora no caso da discricionariedade estrutural para sopesar, qual seja, como a possibilidade de determinar o constitucionalmente devido. Uma vez analisadas a segunda lei da ponderação, suas possíveis interpretações e as diferentes propostas de escala de verificação da insegurança, adverte-se para o fato de que também aqui aquele princípio formal é essencial, razão pela qual se busca analisar seu conceito e as teorias a respeito da sua relação com os princípios materiais para, então, propor que o reconhecimento de discricionariedades epistêmicas em favor do legislador decorra, por força da insegurança, de um controle menos intenso das suas decisões, numa verdadeira presunção de proporcionalidade, mas que essa intensidade aumente conforme aumenta a intensidade da intervenção.

Palavras Chave: sopesamento - empates - discricionariedade estrutural para sopesar princípios formais - deferência - discricionariedades epistêmicas - intensidade do controle. 


\begin{abstract}
Balancing faces recurring criticisms, being one of the most common the alleged illegitimacy of its use by the Judiciary Branch. In the context of its reading as optimisation, two aspects can be highlighted: it is claimed that optimisation balancing is unable to limit legislative activity, thus, it does not provide suitable protection to fundamental rights since it allows legislators to disrespect again and again the constitutional framework; and, also, that, as it represents, at the end of the day, the pursuit of the single right answer, its use withdraws from the legislator every single liberty to conform the constitution, thereby undoing that framework with an extreme magnification of the constitutional court's competence to review. So to answer these criticisms, Robert Alexy develops the concept of legislative discretions within his theory of principles. The purpose of this work is, precisely, to analyze how the types of legislative discretion can succeed in limiting the use of the balancing by the Judiciary when performing a review of statutory limitations on fundamental rights. Based upon some premises that demarcate the theoretical framework of this dissertation, namely, Robert Alexy's principles theory, the wide scope and the external theory of fundamental rights, the idea of constitution as framework and the concept of limitation on fundamental rights, it strives for clarifying the two forms of imposing limits to the judicial review, structural discretion in balancing and epistemic discretions. Adopting as starting point the Jurisprudence's discussions, it is argued that, when one speaks of structural discretion in balancing, discretion must be understood as a special type of choice, significantly constrained by reason and institutional role and, also, that discretion - arising as a result of the recognition of a stalemate situation - focuses on a situation that, from a structural point of view, is a genuine moral dilemma and indicates a situation constitutionally not valuated. Having considered such aspects, by virtue of the formal principle of the competence of the legislature democratically legitimized, the court needs to adopt a position of deference with regard to the legislative decision. Regarding the legislator's epistemic discretions, both empirical and normative, respectively arisen from the unreliability of empirical and normative assumptions, it is argued that discretion - in such context - must be seen in a conceptually different manner as it was seen in the structural discretion in balancing - as the possibility of establishing what the Constitution requires. Once the second law of balancing, its possible interpretations, and the different proposals for scale of verification unreliability have been examined, it is argued that such formal principle is also important here, and that is the reason why the concept of the formal principle and the theories about its relation with material principles are also analyzed. Henceforth, it will be proposed that the recognition of epistemic discretions in favor of the legislator results - due to the unreliability - from a less intense control of its decisions, in a true presumption of proportionality, however, this intensity increases accordingly the increase in the intensity of the interference.
\end{abstract}

Keywords: balancing - stalemates - structural discretion in balancing - formal principles - deference - epistemic discretions - intensity of review. 


\section{SUMÁRIO}

INTRODUÇÃO

$1.1 \mathrm{O}$ objeto da dissertação e seus limites.......................................................................

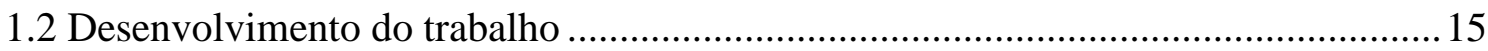

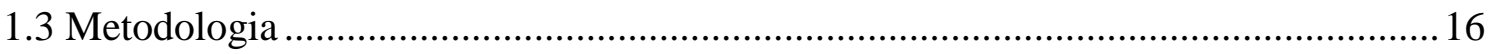

CAPÍTULO 2 - SOBRE O MARCO TEÓRICO DO TRABALHO ……………………......18

2.1 A distinção entre princípios e regras........................................................................... 18

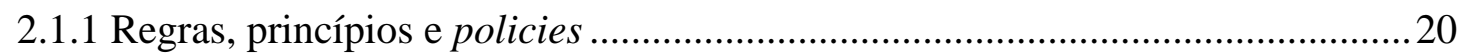

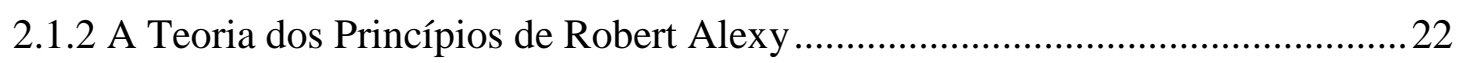

2.1.2.1 Mandamentos de otimização ........................................................................22

2.1.1.2 O distinto caráter prima facie ....................................................................2

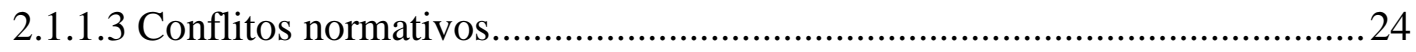

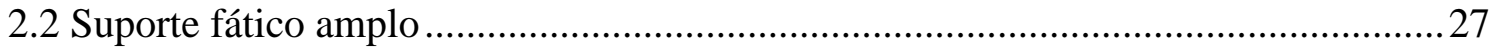

2.3 Teoria externa dos direitos fundamentais ................................................................

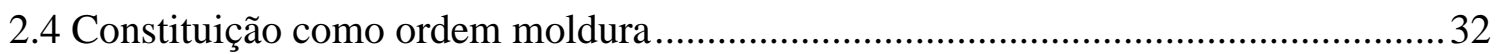

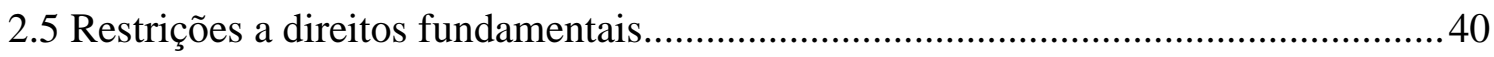

CAPÍTULO 3 - A DISCRICIONARIEDADE ESTRUTURAL DO LEGISLADOR PARA

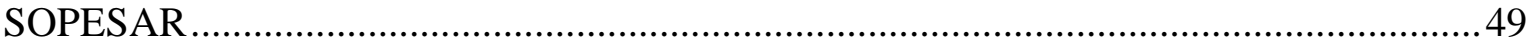

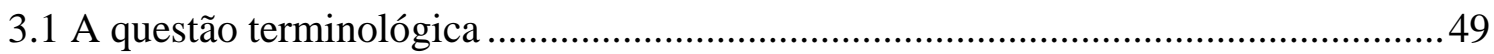

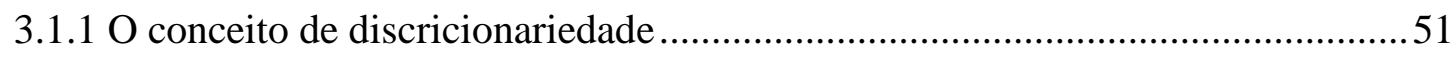

3.1.2 A discricionariedade como conceito relacional ................................................5

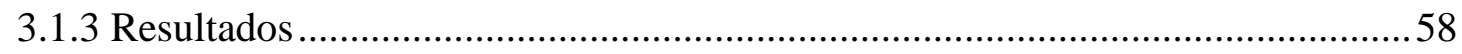

3.2 Discricionariedade estrutural do legislador para sopesar...........................................59

3.3 Discricionariedade para sopesar e âmbitos constitucionalmente não valorados ........81

3.4 Impasses no sopesamento como dilemas morais genuínos ………………………........ 88

3.5 Empates no sopesamento, discricionariedade estrutural para sopesar e deferência ..99

CAPÍTULO 4 - A DISCRICIONARIEDADE EPISTÊMICA DO LEGISLADOR .........109

4.1 A justificação interna e a justificação externa do sopesamento..................................109

$4.2 \mathrm{O}$ problema da insegurança epistêmica....................................................................112

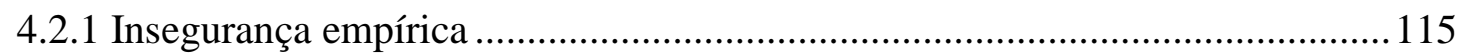

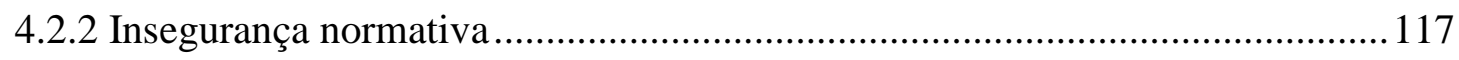


4.2.2.1 A caracterização da insegurança normativa segundo Alexy

4.2.2.2 Insegurança normativa e discricionariedade estrutural para sopesar. 120

4.2.2.3 O objeto da insegurança normativa

4.2.3 O sentido da discricionariedade legislativa na discussão a respeito da segurança epistêmica 125

4.3 O problema da estrutura da segunda lei da ponderação. 128

4.3.1 A segunda lei da ponderação em sua formulação original 128

4.3.2 A crítica e reformulação proposta por Julian Rivers 130

4.3.3 Klatt, Meister e Schmidt e a dependência de perspectiva na segunda lei da ponderação 133

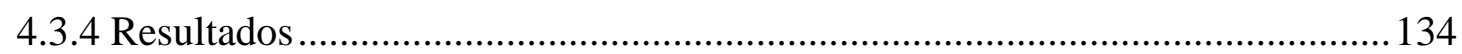

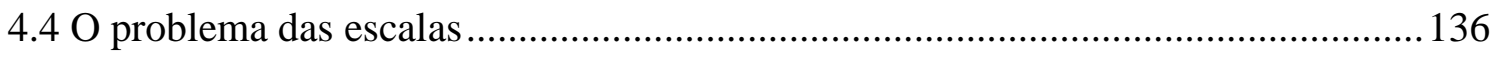

4.4.1 A escala epistêmica de Alexy .......................................................................... 136

4.4.2 A escala de segurança de Klatt, Meister e Schmidt........................................137

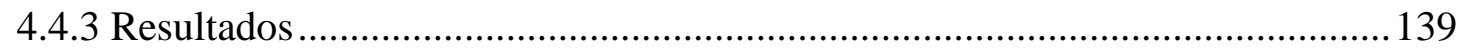

4.5 Discricionariedade epistêmica e princípios formais ............................................... 141

4.5.1 O problema da relação entre princípios formais e discricionariedades

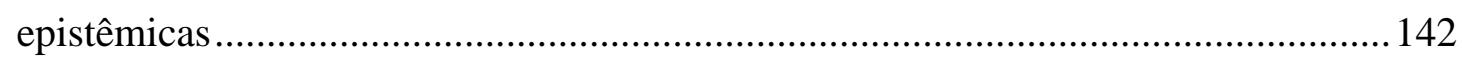

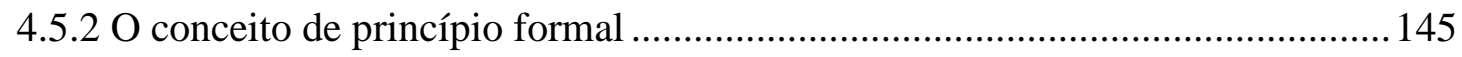

4.5.2.1 O modelo de combinação ...................................................................... 151

4.5.2.2 O modelo das interpretações constitucionais concorrentes ....................... 155

4.5.2.3 O modelo de dois níveis de Klatt, Meister e Schmidt ................................ 161

4.5.2.4 O modelo epistêmico .................................................................................... 165

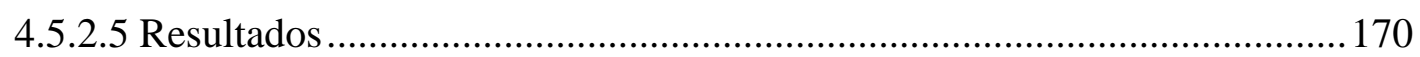

4.6 Discricionariedades epistêmicas do legislador e intensidade do controle ............... 173

4.6.1 O controle de densidade variável do Tribunal Constitucional Federal Alemão173 4.6.2 Reconhecimento discricionariedades legislativas epistêmicas como decorrência

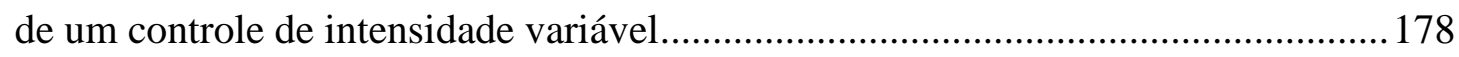

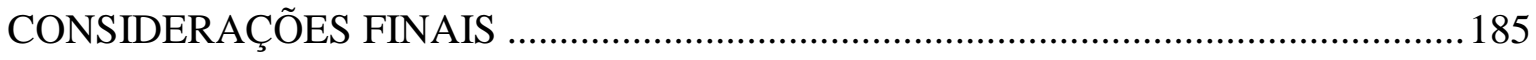

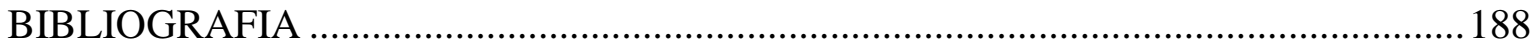




\section{INTRODUÇÃO}

\subsection{O objeto da dissertação e seus limites}

A expansão da proporcionalidade como método de controle da atuação estatal ao redor do mundo é inegável. Não por outro motivo ela já foi considerada como umas características definidoras de um eventual "constitucionalismo global". ${ }^{1}$ Seria de se esperar que essa atmosfera de entusiasmo colocasse o modelo de proporcionalidade que emerge da teoria dos princípios acima de críticas. Contudo, não é o que ocorre. As críticas são muitas, mais ou menos relacionadas à teoria dos princípios em si, e especialmente direcionadas à terceira sub-regra, a proporcionalidade em sentido estrito. ${ }^{2}$

Uma parte importante dessas críticas gira em torno da falta de legitimidade do tribunal constitucional para utilizar o método, que, por sua própria natureza, implicaria valorações e conclusões não passíveis de uma orientação por critérios jurídicos completamente certos, de modo que o intérprete levaria a cabo avaliações subjetivas, e isso seria uma intervenção ilegítima na competência do Parlamento, que, em uma Democracia, é aquele que deve definir as relações de prevalência entre direitos, bens e interesses. Evidentemente, essa redução ilegítima da esfera de atuação do legislador no processo de articulação dos interesses sociais e de configuração da vida política implicaria uma violação do princípio da separação dos poderes. No limite, especialmente tendo em vista a constitucionalização de toda e qualquer questão jurídica que decorreria da noção de

\footnotetext{
${ }^{1}$ Cf. Alec Stone Sweet e Jud Mathews, "Proportionality Balancing and Global Constitutionalism", Columbia Journal of Transnational Law 47 (2008): 73-165.

${ }^{2}$ Para uma ampla discussão a respeito das críticas e das possíveis respostas, Cf., por exemplo, Paula Gorzoni, Ponderação e critérios racionais de decidibilidade na argumentação judicial. São Paulo: Dissertação de Mestrado (Universidade de São Paulo), 2011. Alexy elenca críticas de três ordens: (i) relacionadas à estrutura, (ii) relacionadas à racionalidade e (iii) relacionadas à legitimidade. Como o próprio autor ressalta e daí o risco de qualquer classificação -, entre elas existem vínculos estreitos, na medida em que a legitimidade da ponderação depende de sua racionalidade, e, para esta, é decisiva a estrutura. Cf. Robert Alexy, "La formula del peso", trad. Carlos Bernal Pulido, in Miguel Carbonell (org.), El principio de proporcionalidad y la interpretación constitucional. Quito: Ministerio de Justicia y Derechos Humanos, 2008, p. 13. Daí a menção às críticas de Habermas e Schlink nesta discussão. Para uma outra divisão dessas críticas, Cf. Laura Clérico, El examen de proporcionalidad en el Derecho Constitucional. Buenos Aires: Eudeba, 2009, pp. 294 e ss.
} 
ponderação otimizante, a consequência seria a formação de um "Estado Judicial" ou "Ponderador".

Com isso, especialmente no caso controle de constitucionalidade da legislação restritiva de direitos fundamentais ${ }^{3}$, o sopesamento configuraria perigoso instrumento de intervenção ilegítima do Judiciário, mediante a imposição de suas opções valorativas, na órbita que a Constituição atribui ao legislador, que teria suas competências usurpadas. ${ }^{4}$ "Tolerar o sopesamento judicial significa modificar o padrão democrático." Equilibrar os custos e benefícios das intervenções estatais sobre direitos fundamentais constituiria, por definição, uma atividade política, cujo resultado deve ser produto da discussão entre os representantes dos cidadãos. ${ }^{6}$ A função do tribunal constitucional seria, consequentemente, aplicar o direito e não arbitrar fórmulas políticas de composição de interesses contrapostos. ${ }^{7}$ Sendo, supostamente, um método subjetivo, a sua utilização deveria ficar a cargo do legislador, que é o órgão que pelo menos possui legitimidade democrática. "Por

\footnotetext{
${ }^{3}$ Ainda que de um modo um pouco mais radical, na medida em que se refere à proporcionalidade em sentido amplo, Forsthoff, por exemplo, não vê a possibilidade de se levantar qualquer objeção à sua aplicação na seara administrativa, mas, no campo constitucional, em que é a atuação do legislador que é objeto de controle, a questão se apresenta de modo diverso, pois o âmbito em que está circunscrita a competência é muito maior, já que não há a "ampla rede de relações entre normas e atos que oferecem apoios à aplicação do direito no âmbito administrativo". Cf. Ernst Forsthoff, El Estado de la Sociedad Industrial. El modelo de la República Federal de Alemania, trad. Luis López Guerra e Jaime Nicolás Muñiz. Madrid: Instituto de Estudios Politicos, 1975, pp. 224 e ss. No mesmo sentido, Schlink ressalta que o sopesamento judicial não é problemático, "contanto que os tribunais corrijam sopesamentos de tribunais inferiores ou agências administrativas". Nesses casos, o princípio da proporcionalidade em sentido estrito "não constitui problema algum", na medida em que sua utilização toma por base os limites fixados pelo legislador. Se, contudo, esse sopesamento não ocorre dentro do espaço que o legislador especificou para o Judiciário e a Administração, ele é e continuará a ser problemático. Pode tanto fortalecer quanto enfraquecer os direitos fundamentais e, em ambos os casos, "ele é um problema para a democracia". Cf. Bernhard Schlink, "Proportionality (1)", in Michel Rosenfeld e András Sajó (orgs.), The Oxford Handbook of Comparative Constitutional Law. Oxford, UK: Oxford University Press, 2012, pp. 724 e ss e, do mesmo autor, "El principio de la proporcionalidad", trad. Nuria Pastor Muñoz, in Eduardo Montealegre Lynett, Nathalia Bautista Pizarro e Luis Felipe Vergara Peña (eds.), La ponderación en el derecho - Evolución de uma teoria, apectos críticos y ámbitos de aplicación en el derecho alemán. Bogotá: Universidad Externado de Colombia, 2014, pp. 140 e ss.

${ }^{4}$ Cf. Ernst Forsthoff, El Estado de la Sociedad Industrial, p. 246.

${ }^{5}$ Cf. Bernhard Schlink, "Proportionality (1)," p. 734.

${ }^{6}$ Cf. T. Alexander Aleinikoff, "Constitutional Law in the Age of Balancing", Yale Law Journal 96 (1987), pp. 984 e ss. Para o autor, não cabe sustentar que a legitimidade para ponderar princípios decorre da função que os tribunais teriam de corrigir erros de "cálculo legislativo", pois, na prática, não é possível afirmar com certeza que os tribunais chegarão a uma solução correta em todos os casos, de modo a corrigir apenas as ponderações legislativas incorretas. Não é possível justificar porque os cálculos e a composição de pesos do tribunal estão corretos, de maneira a prevalecerem sobre aqueles efetuados pelo legislador.

7 Cf. Santiago Sánchez González, "De la imponderable ponderación y otras artes del Tribunal Constitucional", Revista Teoría y Realidad Constitucional 12-13 (2003), pp. 376-8. No mesmo sentido, Cf. Gustavo Zagrebelsky, "Estado Constitucional", trad. José Levi Mello do Amaral Júnior e Carlos Bastide Horbach e rev. Ada Pellegrini Grinover, in Carlos Bastide Horbach, José Levi Mello do Amaral Júnior e Roger Stiefelmann Leal (orgs.), Direito Constitucional, Estado de Direito e Democracia - Estudos em Homenagem ao Prof. Manoel Gonçalves Ferreira Filho. São Paulo: Quartier Latin, 2011, p. 304.
} 
que a avaliação subjetiva e política dos tribunais deveria importar mais do que a dos legisladores?"8

A esse respeito, Bernhard Schlink anota, ao criticar a ideia de direitos fundamentais como princípios objetivos e a construção doutrinária que passou a vê-los como mandamentos de otimização, que, como consequência dessas posições, aumentariam as possibilidades de criticar e controlar o Legislativo e seria alterado o próprio papel do tribunal constitucional, que se tornaria predominantemente um foro adicional para o tratamento de problemas sociais e políticos, "um segundo Poder Legislativo". " Sob pena de violação do princípio da separação dos poderes, não poderia o Judiciário “opor à vontade concretizadora do legislador sua própria avaliação". ${ }^{10}$ Seria, portanto, vedado ao juiz ponderar direitos a pretexto de efetuar um controle de constitucionalidade. ${ }^{11}$ Neste contexto, de modo mais específico, é curioso que o postulado da otimização também acabe tachado de ilegítimo por razões exatamente opostas.

De um lado, a caracterização dos princípios como mandamentos de otimização faria com que eles perdessem o seu caráter deontológico e, com isso, a sua força justificatória no contexto da argumentação, o que poderia implicar uma insuficiente efetivação dos direitos fundamentais. Com isso, a proporcionalidade não seria capaz de controlar a atuação do legislador, por permitir que ele desrespeite a moldura constitucional diuturnamente e, dessa forma, acabaria por destruir o "muro de fogo" que protege aqueles

\footnotetext{
${ }^{8}$ Cf. Bernhard Schlink, "Proportionality (1)", p. 732.

${ }^{9}$ Isso implicaria, em termos práticos, que quando uma batalha política contra uma lei fosse perdida e, portanto, o adversário político conseguisse aprová-la, a consequência dessa visão dos direitos fundamentais seria a abertura de uma nova batalha, uma batalha jurídica perante o tribunal. Cf. Bernhard Schlink, "German Constitutional Culture in Transition”, Cardozo Law Review 14 (1993), pp. 729 e ss. Renata Camilo de Oliveira aponta que "a adjudicação orientada por valores assume o status de uma legislação concorrente" $\mathrm{e}$, "nessa relação de concorrência, embora o legislador faça primeiro movimento, o tribunal constitucional (não legitimado democraticamente) detém prevalência." Cf. Renata Camilo de Oliveira, "The Balancing of Values and the Compromising of the Guarantee of Fundamental Rights", in VIIth World Congress of the International Association of Constitutional Law, Balancing and proportionality in constitutional review, Atenas, 2007, pp. 7 e ss. <disponível em

http://www.academia.edu/247683/The Balancing_of Values and the Compromising of the Guarantee of Fundamental_Rights, último acesso em 15.04.2015>.

${ }^{10}$ Cf. Dimitri Dimoulis e Leonardo Martins, Teoria Geral dos Direitos Fundamentais, $2^{\mathrm{a}}$ ed. São Paulo: Revista dos Tribunais, 2009, pp. 228 e ss.

${ }^{11}$ Cf. Leonardo Martins, "Proporcionalidade como critério do controle de constitucionalidade problemas de sua recepção pelo Direito e Jurisdição Constitucional brasileiros”, Revista da Ajuris 33 (2006), pp. 222 e 227 e ss. No mesmo sentido, Cf. Leonardo Martins, "Da distinção entre regras e princípios e seus problemas epistemológicos, lógicos e teórico-jurídicos”, in George Salomão Leite (org.), Dos princípios constitucionais: considerações em torno das normas principiológicas da Constituição, $1^{\text {a }}$ ed. São Paulo: São Paulo: Método, 2008, pp. 344 e ss.
} 
direitos. ${ }^{12}$ Para além daquilo que fosse eliminado pelas sub-regras da adequação e da necessidade, "os princípios permitiriam qualquer solução". "Não haveria nenhuma moldura, já que não existiria nenhum limite." ${ }^{\prime 13} \mathrm{O}$ modelo de otimização, portanto, importaria em uma subconstitucionalização, porque deixaria o legislador completamente livre.

De outro, sustenta-se que o sopesamento e a otimização que lhe é inerente teriam o condão de causar efeitos ainda mais nefastos sobre as instituições do Estado Democrático, pois não só reduziriam a nada a liberdade do legislador como também gerariam uma aceleração do processo de "constitucionalização do direito", no pior dos sentidos possíveis de se atribuir à expressão. Com relação à primeira consequência, a noção de otimização é vista como algo que retira do legislador toda e qualquer liberdade para conformar a constituição, desfazendo, portanto, a moldura constitucional, na medida em que desembocaria em uma contínua a super-revisão judicial. ${ }^{14}$ Isso ocorreria porque, na prática, a otimização equivaleria à busca por uma única solução correta: "O postulado da otimização, entendido como comando jurídico-constitucional, torna incompatível uma ampla jurisprudência constitucional com a liberdade de criação do legislador parlamentar", razão pela qual, se rigorosamente conduzido, "tem que absorver necessariamente aquele campo de criação política". ${ }^{15}$ Se tudo faz parte da moldura, então não há quadro e, com isso, perde sentido inclusive falar em moldura.

Isso importaria - daí o segundo problema - na consequência que Forsthoff, ironicamente, apontou, ao afirmar que a chamada Constituição total corresponderia a "um genoma jurídico, do qual tudo surge, desde o Código Penal até a Lei sobre a fabricação de termômetros". A Constituição se torna uma ordem total, da qual tudo deriva e que regulamenta toda a vida social, e a legislação se converte em mera execução de suas

${ }^{12}$ Cf. Jürgen Habermas, Between Facts and Norms: Contributions to a Discourse Theory of Law and Democracy, trad. William Rehg. Cambridge, MA: MIT Press, 2006, pp. 253 e ss.

${ }^{13}$ Cf. Robert Alexy, Teoria dos Direitos Fundamentais, trad. Virgílio Afonso da Silva, $1^{\text {a }}$ ed. São Paulo: Malheiros, 2008, p. 594.

${ }^{14}$ Cf. Ernst-Wolfgang Böckenförde, Sobre la situación de ta dogmática de los derechos fundamental em los 40 anos de Ley Fundamental", trad. Juan Luis Requejo, in Escritos sobre derechos fundamentales, BadenBaden: Nomos, 1993, pp. 127 e ss. e Christian Starck, Jurisdicción Constitucional y derechos fundamentales, trad. Maria J. Roca. Madrid: Dykinson, 2011, pp. 112-3.

${ }^{15}$ Cf. Rainer Wahl, "O primado da Constituição", trad. Antônio Francisco de Souza, Revista da Ordem dos Advogados 47 (1987), pp. 88-90. Em outra passagem, Wahl afirma que, se há uma obrigação de satisfazer uma eficácia ótima, "então só pode existir uma única solução". No mesmo sentido, Cf. Luis Prieto Sanchís, "Notas sobre la interpretación constitucional", Revista del Centro de Estudios Constitucionales 9 (1991), pp. 176 e ss. e Angel Carrasco Perera, "El 'juicio de razonabilidad' en la justicia constitucional", Revista Española de Derecho Constitucional 11 (1984), pp. 52 e ss. 
normas. Todos os problemas jurídicos seriam problemas constitucionais ${ }^{16}$, ou, especificamente no que se refere à teoria dos princípios, todos os problemas sociais e políticos poderiam ser reconstruídos como problemas de direitos fundamentais. ${ }^{17} \mathrm{Na}$ prática, isso significaria que todas as decisões do legislador seriam passíveis de controle, de tal sorte que não haveria qualquer discricionariedade para conformação da Constituição. ${ }^{18}$ A ponderação seria, assim, um caminho sem volta para a consolidação de um Estado Judicial, um Estado Ponderador, em que o Judiciário, especialmente o tribunal constitucional, acabaria por se tornar um legislador complementar, um supercondutor dos demais poderes, enfraquecendo o Legislativo com a absorção de suas competências. ${ }^{19}$ É para responder a essas críticas que Alexy desenvolve a noção de discricionariedades legislativas, que constituem o objeto deste estudo.

É importante notar que o objetivo aqui é analisar o papel das diversas espécies de discricionariedade legislativa como limites ao uso da proporcionalidade em sentido estrito pelo judiciário quando do controle de constitucionalidade da legislação restritiva de direitos fundamentais. Isso esclarece os limites do tema. Em primeiro lugar, o objetivo é analisar restrições legislativas a direitos fundamentais. A razão de ser da escolha reside no fato de que, como a exposição acima demonstra, há certamente mais objeções em relação à utilização do sopesamento no controle de decisões legislativas, especialmente tendo em vista a competência do legislador para conformar a Constituição. Além disso, a escolha permite não só analisar um modelo compatível com a resposta a essas críticas, mas também como isso se relaciona com as formas de reconstrução da autoridade das decisões do legislador. Em segundo lugar, não se trata de uma análise da proporcionalidade como um todo, e, tampouco, da ponderação autônoma - que não faria sentido no caso do controle da legislação restritiva de direitos fundamentais. ${ }^{20}$ A opção, aqui, mais uma vez decorre do

\footnotetext{
${ }^{16}$ Cf. Ernst Forsthoff, El Estado de la Sociedad Industrial, p. 241.

17 Essa é a advertência de Schlink: “(...) neste mundo, onde todas as esferas de liberdade são esferas fundamentalmente protegidas e todas as limitações de esferas de liberdade são sancionadas limitações sufragadas pelo Estado, todos os problemas da vida social são essencialmente problemas de direitos fundamentais.” Cf. Bernhard Schink, "German Constitutional Culture in Transition”, p. 721.

${ }^{18}$ Cf. Leonardo Martins, "Da distinção entre regras e princípios", p. 345.

${ }^{19}$ Conforme anota Böckenförde, "o Tribunal Constitucional se converte no senhor da Constituição", por força de "uma mudança na ordenação dos poderes e uma troca do centro de gravidade entre eles", o que produziria "um trânsito escorregadio do Estado Legislativo Parlamentar para o Estado Jurisdicional de justiça constitucional". Cf. Ernst-Wolfgang Böckenförde, "Sobre la situación de la dogmática de los derechos fundamental en los 40 anos de Ley Fundamental", p. 135.

${ }^{20}$ Embora tanto a proporcionalidade em sentido estrito quanto a ponderação autônoma constituam sopesamentos, as suas hipóteses de aplicação são diferentes. Muitos casos de colisão entre princípios são solucionadas pelo legislador. Nesses casos, ele efetua um sopesamento entre os princípios colidentes, cujo resultado corresponde a uma regra que dá prevalência a um deles. Ocorre que, em muitos casos, não há
} 
fato de que, como ficou claro nas considerações anteriores, em relação à proporcionalidade em sentido estrito as críticas são naturalmente mais intensas. Relativamente à adequação e à necessidade, o são pela sua própria natureza de sopesamento. ${ }^{21}$ Quanto à ponderação autônoma porque, conforme exposto, o que se controla é uma decisão do legislador. ${ }^{22}$

A minha hipótese é que, a partir da "dimensão formal dos direitos fundamentais" e, portanto, da noção de "discricionariedade legislativa" e dos chamados "princípios formais", é possível reconstruir um modelo de sopesamento capaz de superar as críticas expostas acima, e, portanto, compatível com a autoridade das decisões do legislador, na medida em que limita a competência de controle do tribunal quando da realização do sopesamento e exige dele uma certa deferência para com o Parlamento. ${ }^{23}$ Com isso, é

concordância em relação à constitucionalidade dessa regra, e, naturalmente, é possível contestá-la. A principal forma de verificar a sua constitucionalidade se dá justamente por meio da regra da proporcionalidade. Nessas hipóteses, é necessário indagar (i) se a regra é adequada para fomentar a realização do princípio promovido, (ii) se (se for o caso) não há medida igualmente eficiente, mas menos restritiva e, por fim, novamente se for o caso, (iii) se o grau de promoção é suficiente para compensar o grau de restrição. No entanto, há casos em que não houve uma ponderação pelo legislador, ou seja, não há uma norma infraconstitucional que discipline a colisão entre os princípios. Nesses casos, mais raros, apenas a ponderação entre os direitos será necessária para resolver o caso concreto, já que não faria sentido utilizar a proporcionalidade em sentido amplo, que tem em suas duas primeiras sub-regras métodos que analisam a medida estatal, e nesses casos não há medida alguma. Como nota Virgílio Afonso da Silva, aqui a restrição decorrente da ponderação não encontra fundamento em nenhuma regra infraconstitucional, mas sim na competência do juiz para decidir o caso concreto. No sentido destas considerações, Cf. Virgílio Afonso da Silva, Direitos Fundamentais - Conteúdo Essencial, Restrições e Eficácia, $2^{\mathrm{a}}$ ed. São Paulo: Malheiros, 2010 , pp. 142-3 e 178-9 e Rafael Bellem de Lima, Regras na teoria dos princípios. São Paulo: Malheiros, 2015, pp. 111 e ss.

${ }^{21}$ Autores como Pieroth e Schlink (Cf. Bodo Pieroth e Bernhard Schlink, Direitos Fundamentais, trad. Antônio Francisco de Sousa e Antônio Franco, $1^{\mathrm{a}}$ ed. São Paulo: Saraiva, 2011, pp. 142 e ss.) e Dimoulis e Martins (Cf. Dimitri Dimoulis e Leonardo Martins, Teoria Geral dos Direitos Fundamentais, $2^{\mathrm{a}}$ ed. São Paulo: Revista dos Tribunais, 2010, pp. 228 e ss.), não obstante não tenham nada a objetar em relação às duas (primeiras) regras da proporcionalidade (adequação e necessidade), não aceitam - pelo menos quando se trata do controle da atividade do legislador - a inclusão da proporcionalidade em sentido estrito no exame, ainda que os dois primeiros façam menção a essa possibilidade nos casos (excepcionais) em que, após os testes da adequação e da necessidade, ainda permanece a "impressão de absurdez" da intervenção estatal.

${ }^{22}$ Até porque criticar a ponderação autônoma nos mesmos termos seria de um extremismo. É impossível que o legislador resolva todos os possíveis casos de colisões entre direitos fundamentais. A ponderação, nesses casos, decorre da própria competência do Judiciário para solucionar controvérsias. Valem, neste ponto, as observações de Sieckmann, segundo o qual, "quando se trata de decisões sobre conflitos horizontais, entre as partes que se encontram em igualdade - no direito civil, por exemplo -, as ponderações podem se justificar mais facilmente em razão da necessidade de uma decisão oficial". Cf. Jan-R. Sieckmann, "Problemas de la teoría principialista de los derechos fundamentales", trad. Daniel Oliver-Lalana, in Laura Clérico, Jan-R. Sieckmann e Daniel Oliver-Lalana (coords.), Derechos fundamentales, principios y argumentación: estudios sobre la teoría jurídica de Robert Alexy. Granada: Comares, 2011, p. 37, nota 67.

${ }^{23}$ Apesar das conclusões - corretas - de que não é possível "formular uma regra simples que separe, com clareza e em todos os casos, a competência decisória do legislador da competência de controle do tribunal constitucional" (Cf. Robert Alexy, Teoria dos Direitos Fundamentais, p. 546) e de que essa busca "está fadada ao fracasso" (Cf. Virgílio Afonso da Silva, "Direitos fundamentais e liberdade legislativa: o papel dos princípios formais", in Fernando Alves Correia, Jónatas E. M. Machado e João Carlos Loureiro (orgs.), Estudos em homenagem ao Prof. Doutor José Joaquim Gomes Canotilho, $1^{a}$ ed. Coimbra: Coimbra Editora, 2012, v. III, p. 963), isso não quer dizer que seja igualmente impossível traçar alguns parâmetros e, assim, esclarecer pelo menos parte das questões acerca do problema. 
possível também de fornecer uma constitucionalização adequada, apta a evitar os riscos tanto da subconstitucionalização quanto da hiperconstitucionalização, e compatível, portanto, com a noção da Constituição como ordem-moldura.

\subsection{Desenvolvimento do trabalho}

A presente dissertação é dividida em cinco capítulos. Após a apresentação e delimitação do tema nesta introdução, esclareço, no segundo capítulo, qual o marco teórico no âmbito do qual trabalho, isto é, quais são as premissas teóricas de que partem os argumentos desta dissertação. Essas premissas são, em síntese, $(i)$ a teoria dos princípios de Robert Alexy, (ii) a teoria do suporte fático amplo dos direitos fundamentais, (iii) a teoria externa dos direitos fundamentais e (iv) a noção de Constituição como ordem moldura. A partir dessas premissas, pretendo esclarecer o conceito de restrição de que parto, e, bem assim, o tipo específico que me interessa aqui.

No terceiro capítulo, abordo a discricionariedade estrutural do legislador para sopesar. Este capítulo possui cinco tópicos. No primeiro, procuro explicitar o conceito de discricionariedade de que parto neste caso, valendo-me das discussões da teoria do direito. No segundo, analiso a ideia de discricionariedade estrutural para sopesar. Nos dois seguintes, passo à análise de duas noções correlatas, que permitem uma melhor compreensão do tema e justificam porque podemos entender que casos de discricionariedade estrutural para sopesar são, do ponto de vista estrutural, dilemas morais genuínos e configuram âmbitos não valorados constitucionalmente. Por fim, sustento que o reconhecimento de uma discricionariedade em favor do legislador exige do tribunal, por força do princípio formal da competência do legislador democraticamente legitimado, uma postura de deferência com relação à decisão legislativa.

No quarto capítulo, trato das discricionariedades epistêmicas do legislador, tanto a de tipo empírico quanto a de tipo normativo. Após ressaltar que a discussão sobre essa espécie de discricionariedade está inserida na problemática da justificação externa do sopesamento e que incide sobre as hipóteses de incerteza, procuro esclarecer em que consistem os objetos da insegurança empírica e da insegurança normativa. Feitos esses esclarecimentos, ressalto que o conceito de discricionariedade aqui é diverso daquele do capítulo anterior e passo à análise da segunda lei da ponderação e suas possíveis interpretações e das diferentes propostas de escala de verificação da insegurança. Deixo 
claro, posteriormente, que o princípio formal da competência do legislador é essencial também nesta espécie de discricionariedade e, depois de conceituar essa subespécie normativa, analiso as diferentes propostas de relacionamento daquele princípio formal com os princípios materiais. Proponho, finalmente, que o reconhecimento de discricionariedades epistêmicas em favor do legislador enseje um controle menos intenso das decisões daquele órgão, numa verdadeira presunção de proporcionalidade, mas que essa intensidade aumente conforme aumenta a intensidade da intervenção.

Por fim, no último capítulo, faço, sem qualquer pretensão de retomar ou resumir os argumentos desenvolvidos, algumas considerações finais a respeito do trabalho.

\subsection{Metodologia}

O enfoque do presente trabalho pode ser considerado essencialmente dogmático. No interior dogmática, partindo da divisão proposta por Robert Alexy, a investigação pode ser caracterizada como analítica, empírica e normativa. ${ }^{24}$

No que se refere à dimensão analítica - certamente a que prevalece -, que tem por objeto a análise de conceitos elementares, a construção de estruturas jurídicas, o exame da estrutura do sistema jurídico e a fundamentação no âmbito dos direitos fundamentais, a sua presença pode ser notada tanto nos pressupostos adotados quanto no objeto do trabalho em si. Quanto aos primeiros, por força da análise dos direitos fundamentais como princípios, do conceito de Constituição como moldura, do suporte fático amplo, da teoria externa desses direitos e do conceito de restrição. Quanto ao segundo, isso é verificado tanto na discussão a respeito discricionariedade estrutural para sopesar quanto na das discricionariedades epistêmicas de tipo empírico e de tipo normativo.

Quanto à dimensão empírica, destinada a tratar tanto da cognição do direito positivo válido quanto da aplicação das premissas empíricas na argumentação jurídica, pode-se dizer que o trabalho a reflete na medida em que buscará, tanto quanto possível, trazer exemplos de utilização da terceira regra da proporcionalidade quando do exame da constitucionalidade de leis restritivas de direitos fundamentais, a fim de explicar a relação

\footnotetext{
${ }^{24}$ Essas são as três dimensões da dogmática jurídica segundo Alexy. A esse respeito, Cf. Robert Alexy, Teoria dos Direitos Fundamentais, pp. 33-8 e, de modo semelhante, Robert Alexy, A Theory of Legal Argumentation: The Theory of Rational Discourse as Theory of Legal Justification, trad. Ruth Adler e Neil MacCormick. Oxford, UK: Oxford University Press, 1989, pp. 151-2.
} 
entre as discricionariedades e o sopesamento e fundamentar os argumentos desenvolvidos a esse respeito, o que, de resto, é primordial para uma correta compreensão do tema.

Por fim, a dimensão normativa, relacionada à ideia de respostas corretas para determinados problemas, constitui o objetivo do trabalho como um todo, uma vez que a investigação pretende fornecer elementos para um modelo adequado de sopesamento, isto é, um modelo de sopesamento compatível com as competências do legislador e com a autoridade de suas decisões. 


\section{CONSIDERAÇÕES FINAIS}

Neste último ponto, a pretensão não é listar as conclusões a respeito de todos os aspectos da investigação. Um enfoque como esse seria provavelmente empobrecedor e repetitivo, além de apto a simplificar - equivocadamente - um fenômeno por natureza complexo. Este capítulo limita-se à exposição de algumas considerações finais a respeito do trabalho.

O objetivo desta dissertação era, no contexto da acusação de ilegitimidade que incide sobre o uso da proporcionalidade em geral e da proporcionalidade em sentido estrito pelo Poder Judiciário quando do controle de constitucionalidade de leis que restringem direitos fundamentais e da resposta da teoria dos princípios calcada em uma teoria das discricionariedades legislativa, explicar em que exatamente consistem essas discricionariedades, em que hipóteses incidem e que consequências geram e, com isso, esclarecer como elas limitam a atuação dos tribunais. Essa limitação, por sua vez, deixa claro que não há qualquer incompatibilidade entre a proporcionalidade em sentido estrito e a Constituição como ordem moldura.

Isso se aplica, antes de tudo, à discricionariedade estrutural para sopesar, que incide sobre os casos de empate no sopesamento, em que, portanto, o aplicador se encontra diante de um impasse. O legislador, diante de uma situação que do ponto de vista estrutural pode ser considerada um verdadeiro dilema moral genuíno, opta por promover um dos princípios constitucionais em detrimento do outro mediante uma decisão autoritativa que, para além das restrições inerentes ao conceito de discricionariedade, é livre, na medida em que diz respeito a situações constitucionalmente não valoradas. A autoridade desse tipo de decisão decorre justamente do princípio formal da competência do legislador democraticamente legitimado, que justifica, em contrapartida, a deferência devida pelo tribunal ao Parlamento neste caso.

O mesmo pode ser dito quanto à discricionariedade epistêmica, seja de tipo empírico, seja de tipo normativo, que se aplica às hipóteses de incerteza a respeito do 
constitucionalmente devido. Como no mais das vezes, a despeito da insegurança, uma decisão se faz necessária, o princípio formal da competência do legislador lhe confere a possibilidade de decidir a partir de suas próprias valorações fáticas e normativas, o que nada mais é do que uma espécie de presunção de proporcionalidade assumida pelo tribunal. Aqui, no entanto, pela própria natureza da questão, que justifica inclusive a utilização de um conceito de discricionariedade diverso, o aumento da intensidade da intervenção sobre o princípio restringido justifica uma maior exigência de segurança epistêmica, o que, por sua vez, é fundamento para um controle mais intenso da decisão do legislador. Desse modo, aqui, a discricionariedade legislativa e a sua contraparte deferência judicial possuem um caráter relativo, e tem seu âmbito cada vez menor conforme aumenta a intensidade da intervenção, até o ponto em que, dado alto grau de detrimento do princípio restringido, elas efetivamente desaparecem.

A limitação da atuação dos tribunais e a consequente garantia da autoridade das decisões ponderativas do legislador, desse modo, é promovida tanto mediante a previsão de que naquelas situações em que a argumentação constitucional não leva a uma solução e que, por conseguinte, a própria Constituição não decidiu de modo definitivo deve prevalecer a opção do legislador, quanto por meio do esclarecimento de que em caso de insegurança epistêmica devemos aceitar as valorações do legislador, ainda que apenas até o limite em que a intensidade da intervenção atinge um grau em que a presunção em favor do legislador perde o sentido porque a chance de tratar-se de uma violação da Constituição é maior.

Com essas considerações, podemos, enfim, colocar a proporcionalidade em seu devido lugar. Por um lado, não se recai na tentadora visão de buscar nela uma fórmula mágica para resolver todos os problemas do mundo e, a partir dos seus postulados, localizar na Constituição a solução para toda e qualquer questão social, transformando o tribunal constitucional no oráculo da cidadania. Por outro, não se opta por perfilharse junto daqueles que veem na proporcionalidade um cavalo de Tróia inserido no Estado Democrático, como se um método de controle, por si só, fosse capaz de desvirtuar a Democracia. Afastados, como em regra é sempre o melhor caminho, os arroubos extremistas do otimismo ingênuo e do pessimismo injustificado, a proporcionalidade (em geral e em sentido estrito) assume o posto que lhe pertence por natureza: um dentre muitos métodos de verificação do acerto de uma decisão legislativa, que, se tiver seus pressupostos de aplicação e limites respeitados, tenderá a 
conduzir a bons resultados. Não exigirá nem demais, nem de menos, mas apenas o suficiente para garantir a prevalência da Constituição. 


\section{BIBLIOGRAFIA}

Aarnio, Aulis. "Las reglas en serio", in Ernesto Garzón Valdés e Jyrki Uusitalo (eds.), La Normatividad del derecho. Barcelona: Editorial Gedisa, 1997, pp. 17-33.

Aleinikoff, T. Alexander. "Constitutional Law in the Age of Balancing", Yale Law Journal 96 (1987): 943-1005.

Alexy, Robert. A Theory of Constitutional Rights, trad. Julian Rivers. Oxford, UK: Oxford University Press, 2002.

A Theory of Legal Argumentation: The Theory of Rational Discourse as Theory of Legal Justification, trad. Ruth Adler e Neil MacCormick. Oxford, UK: Oxford University Press, 1989.

"Balancing, constitutional review, and representation", International Journal of Constitutional Law 3 (2005): 572-581.

"Colisão de direitos fundamentais e realização de direitos fundamentais no Estado Democrático de Direito", trad. Luís Afonso Heck, Revista de Direito Administrativo 217 (1999): 67-79.

"Comments and Responses", in Mathias Klatt (ed.), Institutionalized Reason - The Jurisprudence of Robert Alexy. Oxford, UK: Oxford University Press, 2012: 319-356.

“Constitutional Rights and Proportionality”, Revus 22 (2014): 51-65.

"Constitutional Rights, Democracy, and Representation", Ricerche giuridiche 3 (2014): 197-209.

"Deber Ideal", trad. Laura Clérico e Jan-R. Sieckmann, in Laura Clérico, Jan-R. Sieckmann e Daniel Oliver-Lalana (coords.), Derechos fundamentales, principios y argumentación: estudios sobre la teoría jurídica de Robert Alexy. Granada: Comares, 2011: 15-35.

"Derecho constitucional y derecho ordinario", trad. Carlos Bernal Pulido, in Robert Alexy, Tres Escritos sobre los Derechos Fundamentales y la Teoría de los Principios. Bogotá: Universidad Externado de Colombia, 2003: 41-92.

"Epílogo a la Teoría de los Derechos Fundamentales", trad. Carlos Bernal Pulido, Revista Española de Derecho Constitucional 22 (2002): 13-64.

"Formal principles: Some replies to critics", International Journal of Constitutional Law 12 (2014): 511-524. 
"Interpretación jurídica y discurso racional", trad. Luis Villar Borda, in Robert Alexy, Teoría del discurso y derechos humanos. Bogotá: Universidad Externado de Colombia, 1995: 35-61.

"La fórmula del peso", trad. Carlos Bernal Pulido, in Miguel Carbonell (org.), El principio de proporcionalidad y la interpretación constitucional. Quito: Ministerio de Justicia y Derechos Humanos, 2008: 13-42.

"La idea de una teoría procesal de la argumentación jurídica", trad. Carlos de Santiago, in Robert Alexy, Derecho y razón práctica. Ciudad de México: Fontamara, 2010: 59-73.

“Legal Certainty and Correctness", Ratio Juris 28 (2015): 441-451. 433-449.
“On Balancing and Subsumption. A Structural Comparison”, Ratio Juris 16 (2003):

“On Constitutional Rights to Protection", Legisprudence 3 (2009): 1-17.

“On the Structure of Legal Principles”, Ratio Juris 13 (2000): 294-304.

“Problems of Discourse Theory", Crítica 20 (1988) 43-65.

"Sobre la estructura de los principios jurídicos", trad. Carlos Bernal Pulido, in Robert Alexy, Tres Escritos sobre los Derechos Fundamentales y la Teoría de los Principios. Bogotá: Universidad Externado de Colombia, 2003: 93-137.

Teoria dos Direitos Fundamentais, trad. Virgílio Afonso da Silva, $1^{\text {a }}$ ed. São Paulo: Malheiros, 2008.

"The Construction of Constitutional Rights", Law and Ethics of Human Rights 4 (2010): 465-477.

“The Dual Nature of Law”, Ratio Juris 23 (2010): 167-182.

"The Reasonableness of Law", in Giorgio Bongiovanni, Giovanni Sartor e Chiara Valentini (eds.), Reasonableness and Law. Dordrecht: Springer, 2009: 5-15.

“The Special Case Thesis”, Ratio Juris 12 (1999): 374-384.

"Thirteen Replies", in George Pavlakos (org.), Law, Rights and Discourse. The Legal Philosophy of Robert Alexy. Oxford, UK: Hart Publishing, 2007: 333-366.

Allan, Trevor. "Constitutional Rights and the Rule of Law", in Mathias Klatt (ed.), Institutionalized Reason - The Jurisprudence of Robert Alexy. Oxford, UK: Oxford University Press, 2012: 132-151.

Atienza, Manuel. "Constitución y argumentación”, Anuario de filosofía del derecho 24 (2007): 197-228. 
Átria, Fernando. La forma del derecho. Madrid: Marcial Pons, 2016.

Ávila, Humberto. "Conteúdo, limites e intensidade dos controles de razoabilidade, de proporcionalidade e de excessividade das leis", Revista de Direito Administrativo 236 (2004): 369-384.

Teoria dos Princípios - da definição à aplicação dos princípios jurídicos, $12^{\mathrm{a}}$ ed. São Paulo: Malheiros, 2011.

Bachof, Otto. Jueces y constitución, trad. Rodrigo Bercovitz Rodríguez-Cano. Madrid: Civitas, 1987.

Bandeira de Mello, Celso Antônio. Curso de direito administrativo, 27 ed. São Paulo: Malheiros, 2010.

Barak, Aharon. Judicial Discretion, trad. Yadin Kaufmann. New Haven/London: Yale University Press, 1989.

Proportionality: Constitutional Rights and Their Limitations, trad. Doron Kalir. New York: Cambridge University Press, 2012.

Barcellos, Ana Paula de. Ponderação, Racionalidade e Atividade Jurisdicional. Rio de Janeiro: Renovar, 2007.

Barros, Suzana de Toledo de. O princípio da proporcionalidade e o controle de constitucionalidade das leis restritivas de direitos fundamentais, $2^{\mathrm{a}}$ ed. Brasília: Brasília Jurídica, 2000.

Barroso, Luís Roberto. "A razão sem voto: o Supremo Tribunal Federal e o governo da maioria”, Revista Brasileira de Políticas Públicas 5 (2015): 24-50.

Bäcker, Carsten. "Rules, Principles, and Defeasibility", in Martin Borowski, On the Nature of Legal Principles. Stuttgart: Steiner, 2010, pp. 79-91.

Beling, Ernst von. Esquema de derecho penal: la doctrina del delito-tipo, trad. Sebastián Soler. Buenos Aires: Depalma, 1944.

Bellem de Lima, Rafael. Regras na teoria dos princípios. São Paulo: Malheiros, 2015.

Bernal Pulido, Carlos. El principio de proporcionalidad y los derechos fundamentales: el principio de proporcionalidad como criterio para determinar el contenido de los derechos fundamentales vinculante para el legislador, $3^{\mathrm{a}}$ ed. Madrid: Centro de Estudios Políticos y Constitucionales, 2007.

“Estructura y límites de la ponderación”, Doxa 26 (2003): 225:238.

"La Racionalidad de la ponderación”, in Miguel Carbonell (org.), El principio de proporcionalidad y la interpretación constitucional. Quito: Ministerio de Justicia y Derechos Humanos, 2008: 43-68. 
"On Alexy's Weight Formula”, in Agustín J. Menéndez e Erik O. Eriksen (eds.), Arguing Fundamental Rights. Dordrecht: Springer, 2006: 101-110.

"Tribunal Constitucional, Legislador y Principio de Proporcionalidad. Una respuesta a Gloria Lopera”, Revista Española de Derecho Constitucional 74 (2005): 417444.

Bettermann, Klaus-August. "Los límites de los derechos fundamentales", trad. Joaquín Brage Camazano, in Francisco Fernández Segado (ed.), The Spanish Constitution in the European constitutional context: La Constitución española en el contexto constitucional europeo. Madrid: Dykinson, 2003: 1515-1535.

Borowski, Martin. "Derechos de Defensa Como Principios de Derecho Fundamental", trad. Eduardo Sodero, in Jan-R. Sieckmann (coord.), La teoría principialista de los derechos fundamentales: Estudios sobre la teoría de los derechos fundamentales de Robert Alexy. Madrid: Marcial Pons, 2011: 93-118.

"Discourse, Principles, and the Problem of Law and Morality: Robert Alexy's Three Main Works", Jurisprudence. An International Journal of Legal and Political Thought 2 (2011): 575-595.

La estructura de los derechos fundamentales, trad. Carlos Bernal Pulido. Bogotá: Universidad Externado de Colombia, 2003.

"La Restricción de los Derechos Fundamentales", trad. Carlos Bernal Pulido, Revista Española de Derecho Constitucional 20 (2000): 29-56.

"La Sujeción a Determinaciones del Legislador en la Ponderación de Derechos Fundamentales", trad. Daniel Oliver-Lalana, in Laura Clérico, Jan-R. Sieckmann e Daniel Oliver-Lalana (coords.), Derechos fundamentales, principios y argumentación: estudios sobre la teoría jurídica de Robert Alexy. Granada: Comares, 2011: 111-146.

"Principios formales y fórmula del peso", trad. Jorge Portocarrero Quispe, in Jorge Portocarrero Quispe (ed.), Ponderación y discrecionalidad. Un debate en torno al concepto y sentido de los principios formales en la interpretación constitucional. Bogotá: Universidad Externado de Colombia, 2016: 59-158.

"Robert Alexy's Reconstruction of Formal Principles", in Júlio Aguiar de Oliveira, Stanley L. Paulson e Alexandre T. G. Trivisonno (orgs.), Alexy's Theory of Law. Stuttgart: Steiner, 2015: 95-109.

"The Structure of Formal Principles", in Martin Borowski (org.), On the Nature of Legal Principles. Stuttgart: Steiner, 2010: 19-35.

Böckenförde, Ernst-Wolfgang. "Los métodos de la interpretación constitucional Inventario y critica", trad. Ignacio Villaverde Menéndez, in Ernst-Wolfgang Böckenförde, Escritos sobre derechos fundamentales, $1^{\text {a }}$ ed. Baden-Baden: Nomos, 1993: 13-43. 
"Sobre la situación de la dogmática de los derechos fundamental en los 40 años de Ley Fundamental", trad. Juan Luis Requejo, in Ernst-Wolfgang Böckenförde, Escritos sobre derechos fundamentales, $1^{\text {a }}$ ed. Baden-Baden: Nomos, 1993: 95-138.

Brady, Alan. A structural institutionally sensitive model of proportionality and deference under the Human Rights Act 1998. London: PhD Thesis (London School of Economics and Political Science), 2008.

BRASIL. Supremo Tribunal Federal, Pleno, ADI n. 3.937/SP, Rel. Min. Marco Aurélio, julgamento de mérito pendente.

$<$ disponível em

http://www.stf.jus.br/arquivo/cms/noticiaNoticiaStf/anexo/ADI3937relator.pdf, último acesso em 15.04.2016>.

BRASIL. Supremo Tribunal Federal, Pleno, ADI n. 4.650/DF, Rel. Min. Luiz Fux, DJE 24.02.2016.

$<$ disponível em

http://redir.stf.jus.br/paginadorpub/paginador.jsp?docTP=TP\&docID=10329542, último acesso em 15.04.2016>.

BRASIL. Supremo Tribunal Federal, Pleno, HC n. 122.694/SP, Rel. Min. Dias Toffoli, DJE 19.02.2015

<disponível em

http://redir.stf.jus.br/paginadorpub/paginador.jsp?docTP=TP\&docID=10329542, último acesso em 10.10.2016>.

Brage Camazano, Joaquín. Los limites a los derechos fundamentales. Madrid: Dykinson, 2004.

Brink, David O. "Moral Conflict and Its Structure", in H. E. Mason (org.), Moral dilemmas and moral theory. New York: Oxford University Press, 1996: 102-126.

Canotilho, J. J. Gomes. Constituição dirigente e vinculação do legislador: contributo para a compreensão das normas constitucionais programáticas, $2^{\mathrm{a}}$ ed. Coimbra: Coimbra Editora, 2001.

Direito Constitucional e Teoria da Constituição, $7^{\mathrm{a}}$ ed. Coimbra: Almedina, 2000.

"Dogmática de direitos fundamentais e direito privado", in Ingo Wolfgang Sarlet (org.), Constituição, direitos fundamentais e Direito Privado. Porto Alegre: Livraria do Advogado, 2003: 341-359.

Carrasco Perera, Angel. "El 'juicio de razonabilidad' en la justicia constitucional”, Revista Española de Derecho Constitucional 11 (1984): 39-106.

Casal H., Jesús M. “¿Deslindar o restringir? El debate sobre el alcance del ámbito protegido del derecho fundamental en Alemania", Revista Española de Derecho Constitucional 82 (2008): 83-117. 
Castanheira Neves, Antônio. Metodologia jurídica: problemas fundamentais. Coimbra: Coimbra Editora, 2013.

Chang, Ruth. “The Possibility of Parity," Ethics 112 (2002): 659-688.

Chemerinsky, Erwin. Constitutional Law: Principles and Policies, $3^{\mathrm{a}}$ ed. New York: Aspen Publishers, 2006.

Christie, George C. “An Essay on Discretion”, Duke Law Journal 35 (1986): 747-778.

Clérico, Laura. El examen de proporcionalidad en el Derecho Constitucional. Buenos Aires: Eudeba, 2009.

Conee, Earl. "Against moral dilemmas", in Christopher W. Gowans (ed.), Moral Dilemmas. New York: Oxford University Press, 1987: 239-249.

Daley, John. "Defining Judicial Restraint", in Tom Campbell e Jeffrey Goldsworthy (eds.), Judicial Power, Democracy and Legal Positivism. Aldershot: Ashgate, 2000: 314-334.

Dimoulis, Dimitri / Leonardo Martins. Teoria Geral dos Direitos Fundamentais, $2^{\mathrm{a}}$ ed. São Paulo: Revista dos Tribunais, 2009.

Dryzek, John S. / Simon Niemeyer. "Discursive Representation", American Political Science Review 102 (2008): 481-493.

Dworkin, Ronald. Freedom's Law - The Moral Reading of the American Constitution. New York: Oxford University Press, 1996.

Is Democracy Possible Here? Principles For A New Political Debate. Princeton: Princeton University Press, 2007.

Taking Rights Seriously. Cambridge, MA: Harvard University Press, 1977.

Dyzenhaus, David. "Law as Justification: Etienne Mureinik's Conception of Legal Culture", South African Journal on Human Rights 14 (1998): 11-37.

Engisch, Karl. El ámbito de lo no jurídico, trad. Ernesto Garzón Valdés. Cordoba: Universidad Nacional de Cordoba, 1960.

Introdução Ao Pensamento Jurídico, trad. J. Baptista Machado, 9a ed. Lisboa: Fundação Calouste Gulbenkian, 2004.

Fletcher, George P. "Some unwise reflections about discretion", Law and Contemporary Problems 47 (1984): 269-286.

Forsthoff, Ernst. El Estado de la Sociedad Industrial. El modelo de la República Federal de Alemania, trad. Luis López Guerra e Jaime Nicolás Muñiz. Madrid: Instituto de Estudios Politicos, 1975. 
Gardbaum, Stephen. "Limiting Constitutional Rights”, UCLA Law Review 54 (2007): 789854.

"Proportionality and Democratic Constitutionalism", in Grant Huscroft, Bradley Miller e Grégoire Webber, Proportionality and the Rule of Law: Rights, Justification, Reasoning. Cambridge, UK: Cambridge University Press, 2014: 259-283.

Gascón Abellán, Marina Felicia / Juan Gómez Castañeda. "La justicia constitucional: entre legislación y jurisdicción”, Revista Española de Derecho Constitucional 41 (1994): 63-87.

Goodin, Robert E. "Welfare Rights, Law, and Discretion", Oxford Journal of Legal Studies 6 (1986): 232-261.

Gorzoni, Paula. Ponderação e critérios racionais de decidibilidade na argumentação judicial. São Paulo: Dissertação de Mestrado (Universidade de São Paulo), 2011.

Greenspan, Patricia S. "Moral dilemmas and guilt", Philosophical Studies 43 (1983): 117125.

Griffin, James. Well-Being: Its Meaning, Measurement and Moral Importance. Oxford, UK: Clarendon Press, 1986.

Grimm, Dieter. "Constitutional Adjudication and Democracy", Israel Law Review 33 (1999): 193-215.

Guastini, Riccardo. Estudios de teoría constitucional, trad. Miguel Carbonell. Ciudad de México: Fontamara, 2003.

Guzmán Dalbora, José Luis. "La actividad libre de valoración jurídica y el sistema de las causas de justificación en el Derecho Penal", Direito e Ciudadania 16/17 (2003): 23-36.

Habermas, Jürgen. Between Facts and Norms: Contributions to a Discourse Theory of Law and Democracy, trad. William Rehg. Cambridge, MA: MIT Press, 2006.

Harel, Alon / Tsvi Kahana. "The easy core case for judicial review”, Law Journal of Legal Analysis 2 (2010): 227-256.

Hart, HLA. “Discretion”, Harvard Law Review 127 (2013): 652-665.

The Concept of Law, $2^{\mathrm{a}}$ ed. Oxford, UK: Oxford University Press, 1994.

Hart Jr. Henry / Albert Sachs. The Legal Process: Basic Problems in the Making and Application of Law. Cambridge, MA: Tentative Edition, 1958.

Häberle, Peter. Hermenêutica Constitucional - A Sociedade Aberta dos Intérpretes da Constituição: Contribuição para a Interpretação Pluralista e "Procedimental" da Constituição, trad. Gilmar Mendes. Porto Alegre: Sergio Antônio Fabris Editor, 1997.

La garantía del contenido esencial de los derechos fundamentales en la Ley fundamental de Bonn: una contribución a la concepción institucional de los derechos 
fundamentales y a la teoría de la reserva de la ley, trad. Joaquín Brage Camazano. Madrid: Dykinson, 2003.

Heller, Hermann. Teoría del Estado, $3^{\text {a }}$ ed. trad. Luis Tobío. Ciudad de México: Fondo de Cultura Económico, 1955.

Hesse, Konrad. Elementos de Direito Constitucional da República Federal da Alemanha, trad. Luís Afonso Heck. Porto Alegre: Sérgio Antônio Fabris Editora, 1998.

"Significado dos direitos fundamentais", trad. Carlos dos Santos Almeida, in Konrad Hesse, Temas Fundamentais do Direito Constitucional. São Paulo: Saraiva: 56192.

Hirsch, Hans Joachim. "El Derecho penal y el ámbito libre de regulación jurídica", trad. Patricia Ziffer, Doctrina Penal: Teoria y Practica en las Ciencias Penales 39 (1987): $397-$ 424.

Huerta Ochoa, Carla. Conflictos Normativos. Ciudad de México: UNAM, 2003.

"Los conflictos entre normas a luz de la teoría de los principios", in Laura Clérico,

Jan-R. Sieckmann e Daniel Oliver-Lalana (coord.), Derechos fundamentales, principios y argumentación: estudios sobre la teoría jurídica de Robert Alexy. Granada: Comares, 2011: 219-232.

Hurka, Thomas. Perfectionism. New York/Oxford: Oxford University Press, 1993.

Iglesias Vila, Marisa. Facing Judicial Discretion: Legal Knowledge and Right Answers Revisited. Dordrecht: Springer, 2010.

Isensee, Josef. "Los antiguos derechos fundamentales y la Revolución biotecnológica. Perspectivas constitucionales tras el descifrado del genoma humano", trad. Juan Marrodán Ciordia, Persona y Derecho 45 (2001): 139-173.

Jescheck, Hans-Heinrich. Tratado de derecho penal: parte general, trad. José Luis Manzanares Samaniego, 4a ed. Granada: Comares, 1993.

Jestaedt, Matthias. "The Doctrine of Balancing - its Strengths and Weaknesses", in Mathias Klatt (ed.), Institutionalized Reason - The Jurisprudence of Robert Alexy. Oxford, UK: Oxford University Press, 2012: 152-172.

Kaufmann, Arthur. Filosofía Del Derecho, trad. Luis Villar Borda e Ana María Montoya. Bogotá: Universidad Externado de Colombia, 2006.

Kavanagh, Aileen. Constitutional Review under the UK Human Rights Act 1998. Cambridge, UK: Cambridge University Press, 2009.

"Deference or Defiance? The Limits of the Judicial Role in Constitutional Adjudication", in Grant Huscroft (ed.), Expounding the Constitution: Essays in Constitutional Theory. Cambridge, UK: Cambridge University Press, 2008: 184-215. 
"Judicial Restraint in the Pursuit of Justice", University of Toronto Law Journal 60 (2010): 23-40.

Kelsen, Hans. Jurisdição Constitucional, trad. Maria Ermantina Galvão. São Paulo: Martins Fontes, 2003.

Teoria pura do direito, trad. João Baptista Machado, $6^{a}$ ed. São Paulo: Martins Fontes, 1994.

Kett-Straub, Gabriele. "Data Screening of Muslim Sleepers Unconstitutional", German Law Journal 7 (2006): 967-975.

King, Jeff. "Institutional Approaches to Judicial Restraint", Oxford Journal of Legal Studies 28 (2008): 409-441.

Klatt, Matthias. "Balancing competences: How cosmopolitan institutionalism can manage jurisdictional conflicts", Global Constitutionalism 4 (2015): 195-226.

"Positive rights: Who decides? Judicial review in balance", International Journal of Constitutional Law 13 (2015): 354-382.

“Taking Rights Less Seriously - A structural analysis of judicial discretion”, Ratio Juris 20 (2007): 506-529.

Klatt, Matthias / Meister Moritz. "A Máxima da Proporcionalidade: um elemento estrutural do constitucionalismo global", trad. João Costa Neto, Observatório da Jurisdição Constitucional 7 (2014): 23-41.

Press, 2012.

The Constitutional Structure of Proportionality. Oxford, UK. Oxford University

Klatt, Matthias / Johannes Schmidt. "Epistemic discretion in constitutional law", International Journal of Constitutional Law 10 (2012): 69-105.

Espaços no Direito Público. Para a doutrina da ponderação da teoria dos princípios, trad. Luís Afonso Heck. Porto Alegre: Sergio Antonio Fabris Editor, 2015.

Kocourek, Albert. "Formal Relation between Law and Discretion", Illinois Law Review 225 (1914-1915): 225-246.

Kumm, Mattias. "Alexy's Theory of Constitutional Rights and the Problem of Judicial Review", in Mathias Klatt (ed.), Institutionalized Reason - The Jurisprudence of Robert Alexy. Oxford, UK: Oxford University Press, 2012: 201-217.

"Democracy is Not Enough: Rights, Proportionality and the Point of Judicial Review", New York University Public Law and Legal Theory Working Papers 118 (2009): $1-38$.

Lacey, Nicola. "The path not taken: H.L.A. Hart's Harvard essay on discretion", Harvard Law Review 127 (2013): 636-651. 
Larenz, Karl. Metodologia da Ciência do Direito, trad. José Lamego, $3^{\text {a }}$ ed. Lisboa: Fundação Calouste Gulbenkian, 1997.

Laurentis, Lucas Catib de. A proporcionalidade no direito constitucional: origem, modelos e reconstrução dogmática. São Paulo: Tese de Doutorado (Universidade de São Paulo), 2015.

Livingstone, Sonia. "Does TV advertising make children fat?" Public Policy Research 13 (2006): 54-61.

Lemmon, E. J. "Moral dilemmas", in Christopher W. Gowans (ed.), Moral Dilemmas. New York: Oxford University Press, 1987: 101-114.

Lopera Mesa, Gloria Patricia. "El principio de proporcionalidad y los dilemas del constitucionalismo", Revista Española de Derecho Constitucional 73 (2005): 381-410.

McConnell, Michael W. "The Importance of Humility in Judicial Review: A Comment on Ronald Dworkin's Moral Reading of the Constitution", Fordham Law Review 65 (1997): 1269-1293.

McConnell, Terrance. "Moral Dilemmas", in Edward N. Zalta (ed.). The Stanford Encyclopedia of Philosophy, 2014, sem paginação.

<disponível em http://plato.stanford.edu/archives/fall2014/entries/moral-dilemmas, último acesso em 20.01.2016>.

"Moral Residue and Dilemmas", in H. E. Mason (org.), Moral dilemmas and moral theory. New York: Oxford University Press, 1996: 36-47.

MacDonnell, Vanessa. "The Constitution as Framework for Governance", University of Toronto Law Journal 63 (2013): 624-654.

Marcilla, Gema. "Balancing as a Guide to Legislative Reasoning", Legisprudence 4 (2010): 93-104.

"Razón práctica, creación de normas y principio democrático", Anales de la Cátedra Francisco Suarez 47 (2013): 43-85.

Marcus, Ruth. "Moral Dilemmas and Consistency", Christopher W. Gowans (ed.), Moral Dilemmas. New York: Oxford University Press, 1987: 188-204.

"More about Moral Dilemmas", in H. E. Mason (org.), Moral dilemmas and moral theory. New York: Oxford University Press, 1996: 23-35.

Martínez Zorrilla, David. Conflictos constitucionales, ponderación e indeterminación normativa. Barcelona: Tesis Doctoral (Universitat Pompeu Fabra), 2004.

“Dilemas morales y derecho", Discusiones 7 (2008): 17-54.

Martins, Leonardo. "Da distinção entre regras e princípios e seus problemas epistemológicos, lógicos e teórico-jurídicos", in George Salomão Leite (org.), Dos princípios constitucionais: considerações em torno das normas principiológicas da Constituição, $1^{\text {a }}$ ed. São Paulo: São Paulo: Método, 2008: 327-350. 
"Proporcionalidade como critério do controle de constitucionalidade problemas de sua recepção pelo Direito e Jurisdição Constitucional brasileiros", Revista da Ajuris 33 (2006): 193-234.

Mayer, Heinz. "Teoría de la estructura escalonada del orden jurídico", Revista de la Facultad de Derecho de México 244 (2005): 259-270.

Márquez Piñero, Rafael Márquez Piñero. Teoría de la Antijuridicidad. Ciudad de México: Instituto de Investigaciones Jurídicas, 2003.

Mendes, Gilmar. "Âmbito de proteção dos direitos fundamentais e as possíveis limitações", in Gilmar Mendes, Inocêncio Mártires Coelho e Paulo Gustavo Gonet Branco (orgs.), Hermenêutica constitucional e direitos fundamentais. Brasília: Brasília Jurídica, 2000: $210-240$.

Direitos Fundamentais e Controle de Constitucionalidade. Estudos de Direito Constitucional, $4^{\mathrm{a}}$ ed. São Paulo: Saraiva, 2012.

Merkl, Adolf. "Prolegómenos a una teoría de la estructura jurídica escalonada del ordenamiento (I)", trad. Miguel Azpitarte Sánchez e Juan L. Fuentes Osorio, Revista de derecho constitucional europeo 2 (2004): 235-262.

"Prolegómenos a una teoría de la estructura jurídica escalonada del ordenamiento (II)", trad. Miguel Azpitarte Sánchez e Juan L. Fuentes Osorio, Revista de derecho constitucional europeo 3 (2005): 301-326.

Meßerschmid, Klaus. "The Race to Rationality Review and the Score of the German Federal Constitutional Court”, Legisprudence 6 (2012): 347-378.

Michael, Lothar / Martin Morlok. Direitos Fundamentais, trad. Antônio Francisco de Sousa e Antônio Franco. São Paulo: Saraiva.

Miranda, Jorge. Manual de direito constitucional, t. II, $6^{\text {a }}$ ed. Coimbra: Coimbra Editora, 2007.

Moreira Neto, Diogo de Figueiredo. Legitimidade e Discricionariedade: Novas Reflexões sobre os limites e controle da discricionariedade, $2^{\mathrm{a}}$ ed. Rio de Janeiro: Forense, 1991.

Moreso, José Juan. “Alexy y la aritmética de la ponderación”, in Pedro Grández Castro e Miguel Carbonell (eds.), El principio de proporcionalidad en el Derecho contemporáneo. Lima: Palestra Editores, 2010: 59-70.

Legal Indeterminacy and Constitutional Interpretation, trad. Ruth Zimmerling. Springer: Dordrecht, 1998.

Möller, Kai. "Balancing and the Structure of Constitutional Rights", International Journal of Constitutional Law 5 (2007): 453-468. 
2012 .

The Global Model of Constitutional Rights. Oxford, UK: Oxford University Press,

Möllers, Christoph. The Three Branches: A Comparative Model of Separation of Powers. Oxford, UK: Oxford University Press, 2013.

Mureinik, Etienne. "A Bridge to Where? Introducing the Interim Bill of Rights", South African Journal on Human Rights 10 (1994): 31-48.

Müller, Felix / Tobias Richter. "Report on the Bundesverfassungsgericht's Jurisprudence in 2005/2006", German Law Journal 9 (2008): 161-194.

Nagel, Thomas. "The Fragmentation of Value", in Thomas Nagel, Mortal Questions, 15a ed. New York: Cambridge University Press, 2012: 128-141.

Neves, Marcelo. Entre Hidra e Hércules - Princípios e Regras Constitucionais. São Paulo: WMF Martins Fontes, 2013.

Novais, Jorge Reis. As restrições aos direitos fundamentais não expressamente autorizadas pela Constituição. Lisboa: Coimbra Editora, 2003.

Oliver-Lalana, Daniel. "Representación argumentativa y legitimidad democrática en las decisiones judiciales", in Laura Clérico, Jan-R. Sieckmann e Daniel Oliver-Lalana (coords.), Derechos fundamentales, principios y argumentación: estudios sobre la teoría jurídica de Robert Alexy. Granada: Comares, 2011: 147-176.

Oliveira, Renata Camilo de. "The Balancing of Values and the Compromising of the Guarantee of Fundamental Rights", in VIIth World Congress of the International Association of Constitutional Law, Balancing and proportionality in constitutional review, Atenas, 2007, <disponível em http://www.academia.edu/247683/The_Balancing_of_Values_and_the_Compromising_of the_Guarantee_of_Fundamental_Rights, último acesso em 15.04.2015>.

Paula, Felipe de. (De) limitação dos Direitos Fundamentais, $1^{\mathrm{a}}$ ed. Porto Alegre: Livraria do Advogado, 2009.

Peczenik, Aleksander. On Law and Reason. Dordrecht: Springer, 2008.

Peredo Rojas, Marcela. "El Margen de Apreciación del Legislador y el Control del Error Manifiesto. Algunas Consideraciones a partir de la jurisprudencia del Consejo Constitucional Francés y del Tribunal Constitucional Alemán”, Estudios Constitucionales 11 (2013): 47-94.

Pereira, Jane Reis Gonçalves. Interpretação Constitucional e Direitos Fundamentais: uma contribuição ao estudo das restrições aos direitos fundamentais na perspectiva da teoria dos princípios. Rio de Janeiro: Renovar, 2006.

Perry, Stephen. "Second-Order Reasons, Uncertainty and Legal Theory", Southern California Law Review 62 (1989): 913-994. 
Philips, Lothar. "Teoria das normas", trad. Marcos Keel e Manuel Seca de Oliveira, in Arthur Kaufmann e Winfried Hassemer (org.), Introdução à filosofia do direito e à teoria do direito contemporâneas, $2^{\mathrm{a}}$ ed. Lisboa: Fundação Calouste Gulbenkian, 2009: 353-365.

Pieroth, Bodo / Bernhard Schlink. Direitos Fundamentais, trad. Antônio Francisco de Sousa e Antônio Franco, $1^{\text {a }}$ ed. São Paulo: Saraiva, 2011.

Pontes de Miranda, Francisco Cavalcanti. Tratado de Direito Privado: parte geral, vol. 1, $4^{\mathrm{a}}$ ed. São Paulo: Revista dos Tribunais, 1974.

Portocarrero Quispe, Jorge. "El problema de los principios formales en la doctrina de la ponderación de Robert Alexy: Del in dubio pro libertate al in dubio pro legislatore", in Jorge Portocarrero Quispe, Ponderación y discrecionalidad. Un debate en torno al concepto y sentido de los principios formales en la interpretación constitucional. Bogotá: Universidad Externado de Colombia, 2016: 221-260.

"El rol de los principios formales en la determinación del margen de control de constitucionalidad", Revista Derecho del Estado 27 (2011): 75-102.

La ponderación y la autoridad en el derecho. El rol de los principios formales en la interpretación constitucional. Madrid: Marcial Pons, 2016.

Poscher, Ralf. "The Principle Theory: How Many Theories and What is Their Merit?", in Mathias Klatt (ed.), Institutionalized Reason - The Jurisprudence of Robert Alexy. Oxford, UK: Oxford University Press, 2012: 218-247.

Posner, Richard A. "The Meaning of Judicial Self-Restraint", Indiana Law Journal 59 (1983): 1-24.

Powell, H. Jefferson Powell, "Constitutional Virtues", Sixth Annual Walter F. Murphy Lecture in American Constitutionalism - James Madison Program in American Ideals and Institutions. Princeton University, April 24, 2006, sem paginação. <disponível em: http://www.greenbag.org/v9n4/v9n4_powell.pdf, último acesso em 20.03.2016>.

Prieto Sanchís, Luis. Justicia constitucional y derechos fundamentales. Madrid: Trotta, 2003.

"Notas sobre la interpretación constitucional", Revista del Centro de Estudios Constitucionales 9 (1991): 175-198.

Raz, Joseph. Practical Reason and Norms. Oxford, UK: Oxford University Press, 1999.

Ribeiro Neto, João Costa. Entre Cila e Caríbdis: a liberdade de expressão em meio ao conflito entre a discricionariedade do Legislador e a intensidade do controle exercido pelo Juiz Constitucional. Brasília: Tese de Doutorado (Universidade de Brasília), 2015.

Rivers, Julian. "Constitutional Rights and Statutory Limitations", in Mathias Klatt (ed.), Institutionalized Reason - The Jurisprudence of Robert Alexy. Oxford, UK: Oxford University Press, 2012: 248-275. 
"Fundamental Rights in the UK Human Rights Act", in Agustín J. Menéndez e Erik O. Eriksen (eds.), Arguing Fundamental Rights. Dordrecht: Springer, 2006: 141-154.

"Proportionality, Discretion and the Second Law of Balancing", in George Pavlakos (org.), Law, Rights and Discourse. The Legal Philosophy of Robert Alexy. Oxford, UK: Hart Publishing, 2007: 167-188.

"Proportionality and Discretion in international and European law", in Nicholas Tsagourias (ed.), Transnational Constitutionalism. Cambridge, UK: Cambridge University Press, 2007: 107-131.

"Proportionality and Variable Intensity of Review", Cambridge Law Journal 65 (2006): 174-207.

_ “The Presumption of Proportionality", Modern Law Review 77 (2014): 409-433.

Rosenberg, Maurice. "Judicial Discretion of the Trial Court, Viewed from above", Syracuse Law Review 22 (1971): 635-668.

Rubio Llorente, Francisco. La forma del poder: estudios sobre la Constitución. Madrid: Centro de Estudios Constitucionales, 1993.

Sarmento, Daniel. "O neoconstitucionalismo no Brasil: riscos e possibilidades", in Daniel Sarmento (org.), Filosofia e Teoria Constitucional Contemporânea, $1^{\mathrm{a}}$ ed. Rio de Janeiro: Lumen Juris, 2009: 113-146.

"Ubiquidade constitucional: os dois lados da moeda", in Daniel Sarmento (org.), Livres e Iguais: Estudos de Direito Constitucional. Rio de Janeiro: Lumen Juris, 2006: 113-148.

Sartor, Giovanni. "Doing Justice to Rights and Values: Teleological reasoning and proportionality”, Artificial Intelligence and Law 18 (2010): 175-215.

Sánchez González, Santiago. "De la imponderable ponderación y otras artes del Tribunal Constitucional”, Revista Teoría y Realidad Constitucional 12-13 (2003): 351-382.

Schlink, Bernhard. "El principio de la proporcionalidad", trad. Nuria Pastor Muñoz, in Eduardo Montealegre Lynett, Nathalia Bautista Pizarro e Luis Felipe Vergara Peña (eds.), La ponderación en el Derecho - evolución de una teoría, aspectos críticos y ámbitos de aplicación en el Derecho alemán. Bogotá: Universidad del Externado de Colombia, 2014: 117-147. $\overline{711-736 .}$

"German Constitutional Culture in Transition", Cardozo Law Review 14 (1993):

"Proportionality (1)", in Michel Rosenfeld e András Sajó (orgs.), The Oxford Handbook of Comparative Constitutional Law. Oxford, UK: Oxford University Press, 2012: 719-736. 
Schneider, Hans-Peter. "La Constitución - Función y estructura", trad. K-J. Abiez Dohrmann e M. Saavedra López, in Hans-Peter Schneider, Democracia y Constitución. Madrid: Centro de Estudios Constitucionales, 1991: 35-52.

"Jurisdicción constitucional y separación de poderes", trad. Joaquin Abellan, Revista Española de Derecho Constitucional 5 (1982): 35-62.

Schwabe, Jürgen / Leonardo Martins. Cinquenta Anos de Jurisprudência do Tribunal Constitucional Federal Alemão, trad. Beatriz Hennig, Leonardo Martins, Mariana Bigelli de Carvalho, Tereza Maria de Castro e Vivianne Geraldes Ferreira, $1^{a}$ ed. Montevidéu: Fundação Konrad Adenauer, 2005.

Seabra Fagundes, Miguel. "O conceito de mérito no direito administrativo", Revista de Direito Administrativo 23 (1951): 1-16.

Shaw, Geoffrey, "H.L.A. Hart's Lost Essay: Discretion and the Legal Process School", Harvard Law Review 127 (2013): 666-727.

Shiner, Roger A. "Hart on Judicial Discretion", Problema: Anuario de Filosofía y Teoría del Derecho 5 (2011): 341-362.

Sieckmann, Jan-R. "Balancing, Optimisation, and Alexy's 'Weight Formula', in Jan-R Sieckmann, Legal Reasoning: The Methods of Balancing, Proceedings of the Special Workshop "Legal Reasoning: The Methods of Balancing" held at the 24th World Congress of the Association of Legal and Social Philosophy (IVR). Beijing: ARSP-Beiheft, 2010: 103-119.

“Concepciones de la ponderación: Optimización y la 'formula del peso' de Robert Alexy", in Gustavo Beade e Laura Clérico (eds.), Desafios a la ponderación. Bogotá, Universidad Externado de Colombia, 2011: 189-230.

"Principios formales", trad. Francisco Campos Zamora, in Jorge Portocarrero Quispe, Ponderación y discrecionalidad. Un debate en torno al concepto y sentido de los principios formales en la interpretación constitucional. Bogotá: Universidad Externado de Colombia, 2016: 261-309.

"Problemas de la teoría principialista de los derechos fundamentales", trad. Daniel Oliver-Lalana, in Laura Clérico, Jan-R. Sieckmann e Daniel Oliver-Lalana (coords.), Derechos fundamentales, principios y argumentación: estudios sobre la teoría jurídica de Robert Alexy. Granada: Comares, 2011: 37-71.

"La ponderación de los derechos fundamentales como aplicación del derecho: el problema de la restricción de la tributación", in Eduardo Montealegre Lynett, Nathalia Bautista Pizarro e Luis Felipe Vergara Peña (eds.), La ponderación en el Derecho evolución de una teoría, aspectos críticos y ámbitos de aplicación en el Derecho alemán. Bogotá: Universidad del Externado de Colombia, 2014: 63-92.

La teoría del derecho de Robert Alexy. Análisis y crítica. Bogotá: Universidad Externado de Colombia, 2014. 
"Las estructuras lógicas de los argumentos normativos", trad. Carlos Bernal Pulido, in Jan-R Sieckmann, El modelo de los principios Del derecho. Bogotá: Universidad Externado de Colombia, 2006: 81-114.

(2010): $69-91$. 2012.

The Logic of Autonomy. Law and Practical Reason. Oxford, UK: Hart Publishing,

Silva, José Afonso da. Curso de Direito Constitucional Positivo, $30^{\mathrm{a}}$ ed. São Paulo: Malheiros, 2008.

Silva, Virgílio Afonso da. "A Constitucionalidade da Restrição da Publicidade de Alimentos e de Bebidas Não Alcoólicas voltada ao Público Infantil", <disponível em: http://criancaeconsumo.org.br/wpcontent/uploads/2014/02/Parecer_Virgilio_Afonso_6_7_12.pdf, último acesso em 22.11.2016>.

A Constitucionalização do direito: os direitos fundamentais nas relações entre particulares, $1^{\mathrm{a}}$ ed. $2^{\mathrm{a}}$ tir. São Paulo: Malheiros, 2008.

"Comparing the Incommensurable: Constitutional Principles, Balancing and Rational Decision”, Oxford Journal of Legal Studies 31 (2011): 273-301.

Direitos Fundamentais - Conteúdo Essencial, Restrições e Eficácia, $2^{\mathrm{a}}$ ed. São Paulo: Malheiros, 2010.

"Direitos fundamentais e liberdade legislativa: o papel dos princípios formais", in Fernando Alves Correia, Jónatas E. M. Machado e João Carlos Loureiro (orgs.), Estudos em homenagem ao Prof. Doutor José Joaquim Gomes Canotilho, $1^{\mathrm{a}}$ ed. Coimbra: Coimbra Editora, 2012, v. III: 915-937.

"Interpretação constitucional e sincretismo metodológico", in Virgílio Afonso da Silva (org.), Interpretação constitucional, $1^{\text {a }}$ ed., $2^{\text {a }}$ tir. São Paulo: Malheiros, 2005, pp. 115-143.

“O proporcional e o razoável”, Revista dos Tribunais 798 (2002): 23-50.

"Os direitos fundamentais e a lei: a constituição brasileira tem um sistema de reserva legal?", in Cláudio Pereira de Souza Neto, Daniel Sarmento e Gustavo Binenbojm (orgs.), Vinte anos da Constituição Federal de 1988. Rio de Janeiro: Lumen Juris, 2009: 605-618.

"Princípios e regras: mitos e equívocos acerca de uma distinção", Revista LatinoAmericana de Estudos Constitucionais 1 (2003): 607-630.

"Teoría de los principios, competencias para la ponderación y separación de poderes", in Jan-R. Sieckmann (coord.), La teoría principialista de los derechos fundamentales: Estudios sobre la teoría de los derechos fundamentales de Robert Alexy. Madrid: Marcial Pons, 2011: 243-259. 
Simon, Helmut. "La Jurisdicción Constitucional", trad. Antonio López Pina, in Ernst Benda, Werner Maihofer, Hans-Jochen Vogel, Konrad Hesse e Wolfgang Heyde (orgs.), Manual de derecho constitucional, $2^{\mathrm{a}}$ ed. Madrid: Marcial Pons, 2001: 823-861.

Sinnott-Armstrong, Walter. Moral Dilemmas. Oxford, UK: Basil Blackwell, 1988.

"Moral Dilemmas and Rights", in H. E. Mason (org.), Moral dilemmas and moral theory. New York: Oxford University Press, 1996: 48-65.

Starck, Christian. Jurisdicción Constitucional y derechos fundamentales, trad. Maria J. Roca. Madrid: Dykinson, 2011.

Steinmetz, Wilson, “'Farra do boi', fauna e manifestação cultural: uma colisão de princípios constitucionais? Estudo de um acórdão do Supremo Tribunal Federal”, Direitos fundamentais \& justiça 9 (2009): 260-273.

Stern, Klaus. Derecho del Estado de la República Federal Alemana, trad. Javier Perez Royo e Pedro Cruz Villalon. Madrid: Centro de Estudios Constitucionales, 1987.

Sweet, Alec Stone / Jud Mathews. "Proportionality Balancing and Global Constitutionalism", Columbia Journal of Transnational Law 47 (2008): 73-165.

Sunstein, Cass R. Legal Reasoning and Political Conflict. New York: Oxford University Press, 1996.

Tadvald, Marcelo. "Direito litúrgico, direito legal: a polêmica em torno do sacrifício ritual de animais nas religiões afro-gaúchas”, Revista Caminhos 5 (2007): 129-147.

Thayer, James. "The Origin and Scope of the American Doctrine of Constitutional Law", Harvard Law Review 7 (1893): 129-156.

van der Schyff, Gerhard. "Ritual Slaughter and Religious Freedom in a Multilevel Europe: The Wider Importance of the Dutch Case", Oxford Journal of Law and Religion 3 (2014): 76-102.

van Fraassen, Bas C. "Values and the Heart's Command", The Journal of Philosophy 70 (1973): 5-19.

"Singular Terms, Truth-Value Gaps, and Free Logic", The Journal of Philosophy 63 (1966): 481-495.

Wahl, Rainer. "O primado da Constituição", trad. Antônio Francisco de Souza, Revista da Ordem dos Advogados 47 (1987): 61-106.

Waldron, Jeremy. "The Core of the Case against Judicial Review", Yale Law Journal 115, (2006): 1346-1406.

Waluchow, Wilfrid J. "Strong discretion”, Philosophical Quarterly 33 (1983): 321-339. 
Wang, Peng-Hsiang. "Are Rules Exclusionary Reasons in Legal Reasoning?", in Martin Borowski (org.), On the Nature of Legal Principles. Stuttgart: Steiner, 2010: 37-48.

"Formal Principles as Second-Order Reasons", <disponível em:

http://idv.sinica.edu.tw/philaw/documents/Formal\%20Principles\%20as\%20Second\%20Re asons\%20(WANG,\%20final).pdf, último acesso em 15.08.2016>.

Wróblewski, Jerzy. "Legal decision and its justification", Logique et Analyse 53-54 (1971): 409-19.

46.

"Legal syllogism and rationality of judicial decision", Rechtstheorie 5 (1974): 34-

Zagrebelsky, Gustavo. Estado Constitucional, trad. José Levi Mello do Amaral Júnior e Carlos Bastide Horbach e rev. Ada Pellegrini Grinover, in Carlos Bastide Horbach, José Levi Mello do Amaral Júnior e Roger Stiefelmann Leal (orgs.), Direito Constitucional, Estado de Direito e Democracia - Estudos em Homenagem ao Prof. Manoel Gonçalves Ferreira Filho. São Paulo: Quartier Latin, 2011: 291-315.

Zimmerman, Michael J. The Concept of Moral Obligation. New York: Cambridge University Press, 1996.

Zitelmann, Ernst. "Las lagunas del Derecho", trad. Carlos G. Posada, in Friedrich Carl von. Savigny, La ciencia del derecho. Buenos Aires: LOSADA, 1949: 287-322. 